\title{
PERBANDINGAN SIFAT FISIKA AIR SUNGAI CISADANE PADA TATA GUNA LAHAN YANG BERBEDA
}

\author{
Desy Rosarina $^{1)}$, Ellysa Kusuma Laksanawati ${ }^{2)}$ \\ ${ }^{1,2}$ Dosen Program Studi Teknik Industri Universitas Muhammadiyah Tangerang \\ email :desy.rosarina@umt.ac.id
}

\begin{abstract}
Abstrak
Penelitian yang mengkaji kualitas fisika air sungai Cisadane di Kota Tangerang telah dilakukan dari bulan April hingga Juni 2019, bertujuan untuk membandingkan kualitas air sungai Cisadane melalui sifat fisikanya pada tata guna lahan yang berbeda. Penelitian menggunakan metode survei. Penentuan stasiun dilakukan secara purposive sampling, pada tata guna lahan yang berbeda. Tata guna lahan yang diteliti adalah kawasan penangkapan ikan, kawasan pemukiman dan kawasan pabrik.Titik pengambilan sampel untuk area perikanan dan area perumahan berada di Karawaci Hilir (stasiun 1), Babakan (stasiun 2) dan Sukajadi (stasiun 3). Titik pengambilan sampel area pabrik adalah di sekitar pabrik tahu (stasiun 1), pabrik kertas (stasiun 2) dan pabrik minyak kelapa sawit (stasiun 3) semuanya di Karawaci Hilir. Data diukur secara insitu dan di laboratorium yaitu suhu, TDS, warna, bau dan kecerahan.Hasil penelitian menunjukkan bahwa kualitas air di kawasan tangkapan nelayan dan perumahan masih memenuhi baku mutu air. TDS, warna dan kekeruhan tidak memenuhi baku mutu air pada kawasan pabrik. Secara umum, kualitas air sungai Cisadane di kawasan pabrik perlu penanganan khusus untuk mencegah pencemaran lingkungan yang berbahaya bagi ekosistem perairan.
\end{abstract}

Kata Kunci : kualitas air,sifat fisika, pencemaran, sungai Cisadane

\section{PENDAHULUAN}

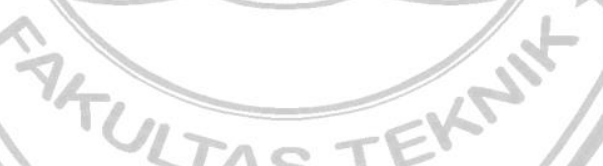

Sungai Cisadane adalah salah satu sungai besar yang melintasi 44 kecamatan di Kabupaten Bogor, Kota Bogor, Kabupaten Tangerang, Kota Tangerang, dan Tangerang Selatansepanjang sekitar $126 \mathrm{~km}$ (Rosarina dan Rosanti, 2018). Perkembangan industri dan pemukiman di sepanjang aliran sungai Cisadane telah mempengaruhi kualitas air sungai. Penurunan kualitas air ditandai dengan perubahan warna air dan bau padahal sebahagian masyarakat di pinggiran sungai masih memanfaatkan air Sungai Cisadane untuk kebutuhan sehari-hari. Suatu sungai dikatakan tercemar jika kualitas airnya sudah tidak sesuai dengan peruntukkannya. Kualitas air ini didasarkan pada baku mutu kualitas air sesuai kelas sungai berdasarkan Peraturan Pemerintah Nomor 82 Tahun 2001 tentang Pengelolaan kualitas Air dan Pengendalian Pencemaran Air.

Air merupakan sumberdaya alam yang harus dilindungi agar tetap dapat dimanfaatkan dengan baik oleh manusia serta makhluk hidup yang lain. Adanya berbagai aktivitas manusia seperti pemukiman warga, pertanian, peternakkan, perikanan dan pariwisata di sekitar badan perairan dapat menyebabkan perubahan-perubahan ekologis. Semakin banyak aktifitas yang terjadi akibat perubahan tata guna lahan, akan semakin banyak limbah yang masuk ke perairan (Rahman et al., 2016).

Tata guna lahan merupakan bagian penting yang mempunyai pengaruh pada kualitas air sungai. Kemampuan daya tampung air sungai yang telah ada secara alamiah terhadap pencemaran perlu dipertahankan untuk meminimalkan terjadinya penurunan kualitas air sungai. Penelitian Rosarina dan 
Laksanawati (2018.a) menyebutkan bahwa penggunaan lahan di sepanjang Sungai Cisadane yang dapat mempengaruhi kualitas air sungai meliputi taman kota, permukiman dan industri, telah mempengaruhi kualitas air sungai melalui buangan yang masuk ke badan air.

Kegiatan masyarakat yang menghasilkan buangan air limbah domestik serta keberadaan industri tekstil dan batik yang membuang air limbahnya ke sungai akan berpengaruh terhadap kualitas air. Pengelolaan kualitas air dilakukan dengan upaya pengendalian pencemaran air, yaitu dengan upaya memelihara fungsi air sehingga kualitas air memenuhi baku mutu (Azwir, 2006 dalam Pohan et al., 2016). Penelitian ini bertujuan untuk menganalisis kualitas air sungai Cisadane berdasarkan parameter fisika.

Salah satu badan perairan adalah sungai, dimana sungai merupakan perairan terbuka yang mendapat masukan dari buangan yang berasal dari kegiatan manusia, yang menyebabkan menurunnya kualitas air (Sahabuddin et al., 2014).Masalah utama yang dihadapi terhadap sumber daya air adalah penurunan kuantitas dan kualitas air karena berbagai aktivitas manusia, diantaranya pemukiman dan industri (Sasongko et al., 2014), termasuk di kawasan Sungai Cisadane Kota Tagerang.

\section{METODE PENELITIAN}

Penelitian dilaksanakan pada Bulan April sampai Juni 2019, berlokasi di perairan Sungai Cisadane pada Kecamatan Karawaci Kota Tangerang. Sedangkan analisa kualitas air dilakukan di UPT Laboratorium Kesehatan Daerah Kota Tangerang.

\section{Penentuan Lokasi}

Penelitian dibagi menjadi 3 kawasan. Setiap kawasan/mewakili tata guna lahan. Kawasan 1 ditentukan di daerah tangkapan ikan (kegiatan perikanan), kawasan 2 di daerah pemukiman dan kawasan 3 di daerah industri (pabrik). Titik sampling pada kawasan tangkapan ikan dan perumahan yaitu di Karawaci hilir (stasiun 1), Babakan (stasiun 2) dan Sukajadi (stasiun 3). Titik sampling kawasan pabrik yaitu di sekitar pabrik pengolahan tahu (stasiun 1), pabrik kertas (stasiun 2) dan pabrik minyak sawit (stasiun 3) semuanya di Karawaci Hilir.

\section{Analisis Data}

Data dinalisis di laboratorium meliputi suhu, TDS, warna, bau dan kecerahan.

\section{Metode Sampling Data}

Penelitian menggunakan metode survey. Pengambilan sampel dilakukan secara purpossive sampling, mengacu pada penelitian Damarany et al. (2009), Agustiningsih et al. (2012), Sahabuddin et al. (2014) dan Sasongko et al. (2014). Disiapkan botol sampel berukuran $600 \mathrm{ml}$ yang terlebih dahulu telah dibersihkan. Dicelupkan botol tersebut ke dalam air dengan posisi miring dengan mulut botol sampel yang menghadap atau berlawanan arus. Botol sampel yang bermuatan $600 \mathrm{ml}$ ini diberi keterangan setiap pengambilan. Ke dalam botol sampel tersebut diukur suhu, TDS, warna, bau, kecerahan. Sampel air disimpan ke dalam lemari pendingin/kulkas yang disediakan di laboratorium.

\section{HASIL DAN PEMBAHASAN}

\section{a. Suhu}

Suhu merupakan faktor penting dalam keberlangsungan proses biologi dan kimia yang terjadi di dalam air, seperti kehidupan dan perkembangbiakan organisme air, karena mempengaruhi kandungan oksigen di dalam air. Suhu air bervariasi antar kedalaman sungai, danau, maupun badan air lainnya.Hasil pengukuran suhu di lapangan dapat dilihat pada gambar 1 dibawah ini : 


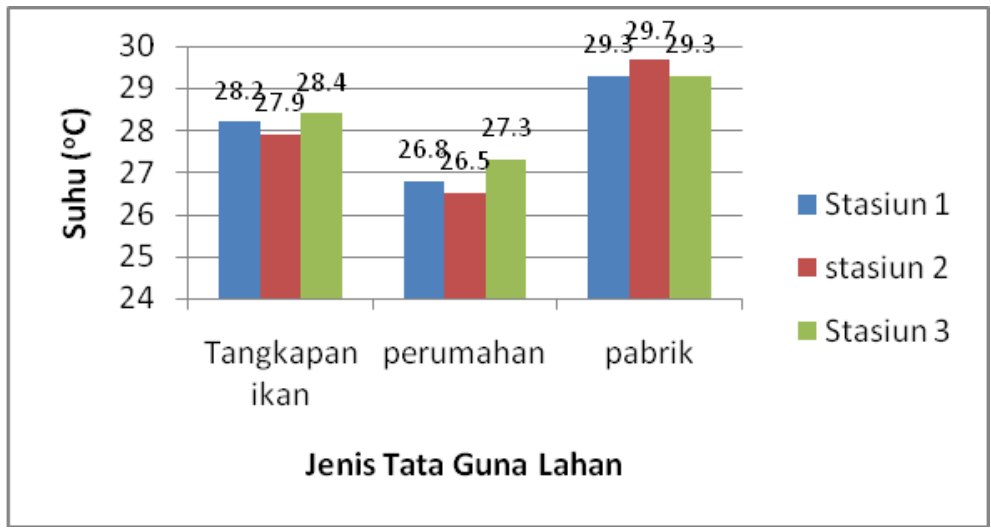

Gambar1. Hasil Pengukuran Parameter Suhu Air

Berdasarkan hasil pengukuran di setiap tata guna lahan diperoleh data suhu berkisar antara $26.5^{\circ} \mathrm{C}-29.7^{\circ} \mathrm{C}$. Kisaran suhu terrendah sampai sedang ada pada kawasan perumahan dan kawasan tanggapan ikan. Hal ini diduga disebabkan oleh banyaknya pepohonan yang tumbuh di sekitar kawasan. Tajuk pohon yang besar dapatmemperlambat daya tembus matahari ke perairan, sehingga menyebabkan suhu di daerah tersebut relatif lebih rendah. Suhu yang demikian dianggap cukup baik, karena menurut Nuriya et al. (2010), kisaran suhu yang optimal bagi kehidupan biota perairan adalah $24^{\circ} \mathrm{C}$ sampai dengan $28^{\circ} \mathrm{C}$

Kisaran suhu tertinggi ada pada kawasan di sekitar pabrik. Tingginya suhu disebakan karena pada kawasan ini vegetasi dengan tajuk pohon yang besar sudah tidak ada lagi, sehingga cahaya matahari yang masuk ke perairan tidak terhalang.Akibat meningkatnya suhu, respirasi biota perairan di sekitarnya juga meningkat, yang biasanya hal ini ditandai dengan kekeruhan air yang tinggi.Tingkat kekeruhan air memang paling tinggi ditemukan pada kawasan sekitar pabrik. Meskipun demikian, kisaran suhu secara keseluruhan masih memenuhi baku butu air kelas II pada PP No 82 tahun 2001, dimana suhu yang dapat ditoleransi oleh biota perairan adalah pada kisaran $28^{\circ} \mathrm{C}-32^{\circ} \mathrm{C}$ deviasi 3 .

\section{b. Total Zat Padat Terlarut (Total Dissolved Solid/TDS)}

Total zat padat terlarut merupakan merupakan padatan yang terlarut dalam larutan baik berupa zat organik maupun anorganik, yaitu semua mineral, garam, logam, serta kation-anion yang terlarut di air. Termasuk semua yang terlarut diluar molekul air murni (H2O). Secara umum, konsentrasi bendabenda padat terlarut merupakan jumlah antara kation dan anion didalam air. Hasil analisa TDS dapat dilihat pada gambar 2 dibawah ini :

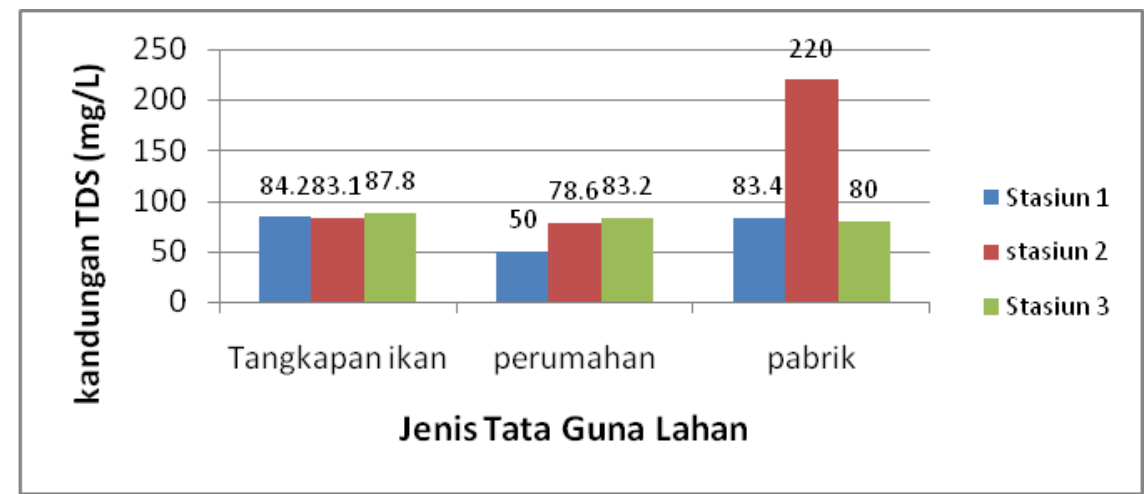

Gambar 2. Hasil Pengukuran TDS (Total Padatan Terlarut) Air

Pada gambar 2 dapat terlihat bahwa nilai total padatan terlarut (TDS) di perairan sungai Cisadane di tiga stasiun masih tergolong memenuhi baku mutu air yaitu masih jauh di bawah 1.000 $\mathrm{mg} / \mathrm{L}$. Kandungan TDS tertinggi terdapat pada stasiun 3 sebesar $64 \mathrm{mg} / \mathrm{L}$ dan nilai TDS terendah terdapat pada kawasan pabrik di stasiun 2 sebesar220 $\mathrm{mg} / \mathrm{L}$. Tingginya nilai TDS pada stasiun 2di 
kawasan pabrik diduga disebabkan dari sumber pencemar dari limbah pabrik kertas yang berupa limbah detergent, bahan-bahan kimiadan kegiatan pabrik lainnya, Menurut Mahyudin et al. (2015), biasanya zat padat terlarut tinggi tinggi karena banyaknya zat padat terlarut oleh berbagai aktivitas manusia.

Baku mutu kualitas air kelas II berdasarkan PP No. 82 tahun 2001 untuk total padatan terlarut maksimum $1.000 \mathrm{mg} / \mathrm{L}$. Nilai total padatan terlarut di ketiga stasiunmasih memenuhi ambang batas baku mutu yang dipersyaratkan. Dengan demikian, kualitas air di ketiga stasiun masih terbilang baik bila ditinjau dari kandungan TDS.

\section{c. Warna dan Bau}

Warna dan bau merupakan faktor fisik yang berhubungan dengan kandungan air, antara lain berkaitan dengan kandungan TDS, TSS, dan BOD. Hasil pengamatan warna dan bau dapat dilihat pada Tabel 1dibawah ini :

Tabel 1. Hasil Pengamatan Warna dan Bau di Stasiun Pengamatan.

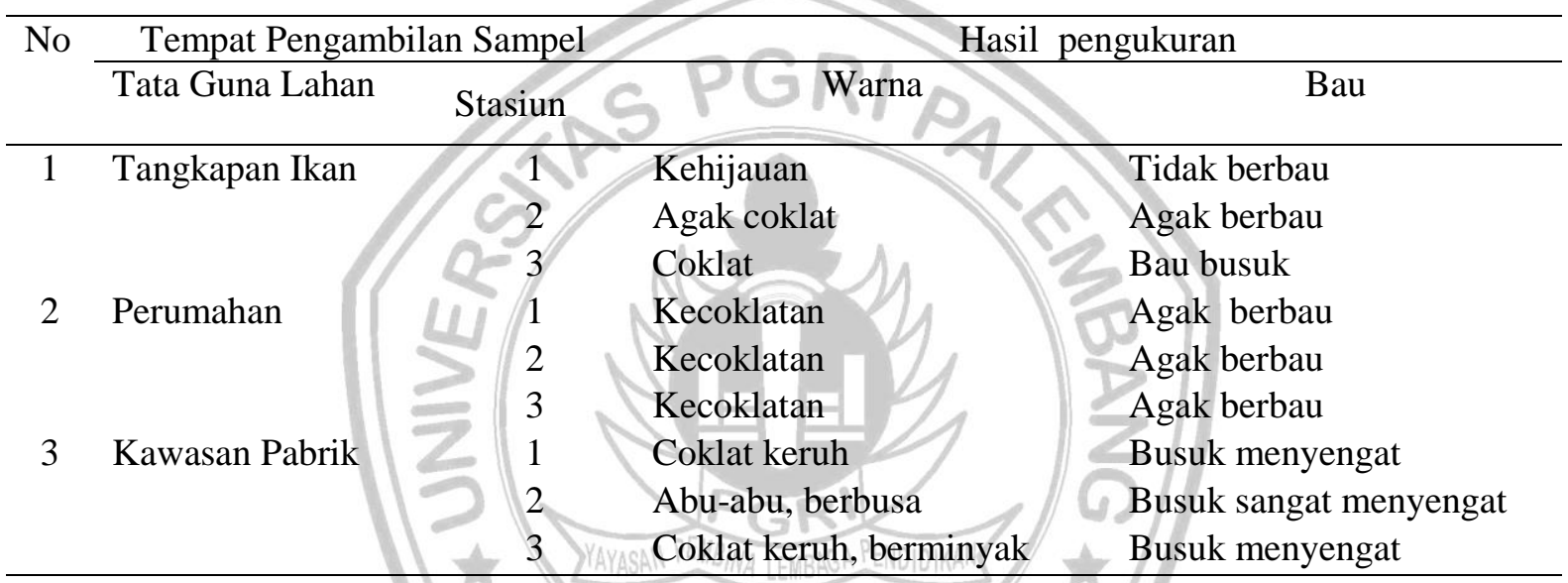

Tabel 1menunjukkan bahwa warna secara umum pada setiap stasiun adalah keruh. Warna keruh diduga disebabkan karena kandungan zat padat tersuspensi yang hampir mencapai nilai setengah baku mutu air. Keruhnya air disebabkan oleh karena letak stasiun tersebut merupakan aliran air yang berasal dari limbah rumah tangga dan pabrik yang mengandung banyak bahan kimia, sabun, minyak sehingga warna air menjadi keruh.

Warna air merupakan hasil refleksi kembali dari berbagai panjang gelombang cahaya sejumlah material yang berada dalam air yang tertangkap oleh mata. Material dalam air dapat berupa jumlah zat tersuspensi (TDS).Faktor-Faktor yang mempengaruhiwarna air bermacam-macam. Adanya warna air tersebut disebabkan oleh beberapa faktor antara lain hadirnya beberapa jenis plankton, baik fitoplankton maupun zooplankton, larutan tersuspensi, dekomposisi bahan organik, mineral ataupun bahan-bahan lain yang terlarut dalam air (Kusmery dan Rosanti, 2015).

\section{d. Kecerahan}

Kecerahan merupakan parameter fisika yang erat kaitannya dengan proses fotosintesis pada suatu ekosistem perairan. Kecerahan menggambarkan sejumlah atau sebagian cahaya yang diteruskan pada kedalaman tertentu. Hasil pengukuran Kecerahan dapat dilihat pada gambar 3 di bawah ini: 


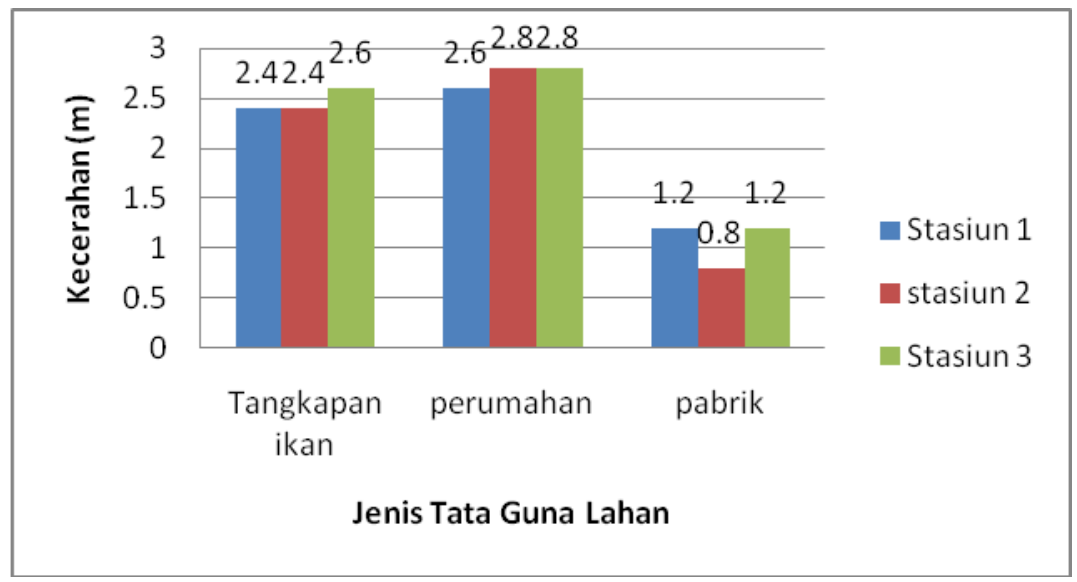

Gambar 3. Hasil Pengukuran Kecerahan Air

Gambar 3 menunjukkantingkat kecerahan pada kawasan tangkapan ikan dan perumahan lebih baik dari pada kawasan pabrik. Tingkat kecerahan yang baik untuk kehidupan biota perairan 30 sampai dengan $40 \mathrm{~cm}$ atau lebih, yang diukur dengan menggunakan secchi disk. Apabila tingkat kecerahan kurang dari $25 \mathrm{~cm}$, akan terjadi penurunan oksigen terlarut secara drastis. Menurut Hamuna et al. (2018), kecerahan yang tinggi menunjukkan daya tembus cahaya matahari yang jauh ke dalam perairan. Begitu juga sebaliknya. Apabila kecerahan tidak baik, berarti perairan itu keruh. Kekeruhan (turbidity) air sangat berpengaruh terhadap kehidupan biota perairan.

\section{KESIMPULAN}

1. Secara fisika, kualitas air di kawasan tangkapan nelayan dan perumahan masih memenuhi baku mutu air. TDS, warna dan kekeurhan tidak memenuhi baku mutu air pada kawasan pabrik.

2. Secara umum, kualitas air sungai Cisadane di kawasan pabrik perlu penanganan khusus untuk mencegah pencemaran lingkungan yang berbahaya bagi ekosistem perairan.

\section{DAFTAR PUSTAKA}

Agustiningsih, D.,S.B.Sasongko dan Sudarno. 2012. Analisis Kualitas Air dan Strategi Pengendalian Pencemaran Air Sungai Blukar Kabupaten Kendal.Jurnal Presipitasi. Volume 9 No 2 September 2012. Universitas Diponegoro.Semarang.

Damarany, P.,M.S.Fachrul dan W.Astono. 2009. Kajian Kualitas Air Sungai Cipinang Bagian Hilir Ditinjau dari Parameter BOD dan DO menggunakan Model Qual2E. Jurnal Teknologi Lingkungan.Vol 5 No 2. Fakultas Teknik Lingkungan Universitas Trisakti. Jakarta.

Hamuna, B. , R.H.R. Tanjung., H.K.Maury dan Alianto. 2018. Kajian Kualitas Air Laut dan Indeks Pencemaran BerdasarkanParameter Fisika-Kimia Di Perairan Distrik Depapre, Jayapura. Jurnal Ilmu Lingkungan. Program Studi Ilmu Lingkungan Sekolah Pascasarjana Universitas Diponegoro. Semarang.

Kusmeri, L. dan D.Rosanti. 2015. Struktur Komunitas Zooplankton di Danau OPI Jakabaring Palembang. Jurnal Sainmatika. Vol 14 No 1. Juni 2015. Fakultas MIPA.Universitas PGRI.Palembang. 
Mahyuddin., Soemarno dan T.B. Prayoga. 2015. Analisis Kualitas Air dan Strategi Pengendalian Pencemaran Air Sungai Metro di Kota Kepanjen Kabupaten Malang.Jurnal Pembangunan dan Alam Lestari. Universitas Brawijaya. Malang. https://jpal.ub.ac.id.

Nuriya, H.,Z. Hidayah dan A.F. Syah. 2010. Analisis Parameter Fisika Kimia di Perairan Sumenep Bagian Timur dengan Menggunakan Citra Lansat TM 5. Jurnal Kelautan. Vol.3 No 2. Universitas Trunojoyo. Madura.

Pohan, D.A.S.,Budiyono dan Syafrudin. 2016. Analisis Kualitas Air Sungai Guna Menentukan Peruntukan Ditinjau dari Aspek Lingkungan. Jurnal Ilmu Lingkungan. Volume 14 Nomor 2. Program Pasca Sarjana. Universitas Diponegoro. Semarang.

Rahman, E.C., Masyamsir dan A. Rizal. Kajian Variabel Kualitas Air dan Hubungannya dengan Produktivitas Primer Fitoplankton di Perairan Waduk Darma Jawa Barat. 2016. Jurnal Perikanan Kelautan.Vol VII No.3. Universitas Padjajaran. Bandung.

Rosarina, D. dan E.K. Laksanawati. 2018.a. Studi Kualitas Air Sungai Cisadane Ditinjau dari Parameter Fisika. Jurnal Redoks. Volume 3 No 2. Fakultas Teknik Universitas PGRI.Palembang.

Rosarina, D. dan D.Rosanti. 2018. Struktur Komunitas Plankton di Sungai Cisadane Kota Tangerang. Prosiding Seminar Nasional Sains dan Teknologi Terapan.Fakultas Saintek UIN Radeh Fatah. Palembang.

Sahabuddin, H.,D.Harisuseno dan E. Yuliani. 2014. Analisa Status Baku Mutu Air dan Daya Tampung Beban Pencemaran Sungai Wanggu Kota Kendari. Jurnal Teknik Pengairan. Vol 5 No.1. Universitas Brawijaya. Malang.

Sasongko, E.B.,E.Widiastuti dan R.E. Priyono. 2014. Kajian Kualitas Air dan Penggunaan Sumur Gali oleh Masyarakat di Sekitar Sungai Kaliyasa Kabupaten Cilacap. Jurnal Ilmu Lingkungan. Volume 12. Program Studi Ilmu Lingkungan. Universitas Diponegoro. Semarang. 